\title{
A systematic study on the effects of dynamic environments on microalgae concentration
}

\author{
Pahija, Ergys; Hui, Chi-Wai
}

Published in:

Algal Research

Link to article, DOI:

10.1016/j.algal.2019.101599

Publication date:

2019

Document Version

Peer reviewed version

Link back to DTU Orbit

Citation (APA):

Pahija, E., \& Hui, C-W. (2019). A systematic study on the effects of dynamic environments on microalgae concentration. Algal Research, 42, [101599]. https://doi.org/10.1016/j.algal.2019.101599

\section{General rights}

Copyright and moral rights for the publications made accessible in the public portal are retained by the authors and/or other copyright owners and it is a condition of accessing publications that users recognise and abide by the legal requirements associated with these rights.

- Users may download and print one copy of any publication from the public portal for the purpose of private study or research.

- You may not further distribute the material or use it for any profit-making activity or commercial gain

- You may freely distribute the URL identifying the publication in the public portal

If you believe that this document breaches copyright please contact us providing details, and we will remove access to the work immediately and investigate your claim. 


\title{
A Systematic Study on the Effects of Dynamic Environments on Microalgae Concentration
}

\author{
Ergys Pahija ${ }^{1,2}$ and Chi-Wai Hui ${ }^{1, *}$ \\ ${ }^{1}$ Department of Chemical and Biological Engineering Department, The Hong Kong University of Science \\ and Technology, Clear Water Bay, Hong Kong SAR \\ ${ }^{2}$ PROSYS Research Center, Department of Chemical and Biochemical Engineering, Technical University \\ of Denmark, Kgs. Lyngby, Denmark \\ *Email: kehui@ust.hk
}

\begin{abstract}
The usage of calibration curves for the determination of microalgae concentration is common, and it consists of a correlation between the optical density and the number of cells. Although this tool is very useful for determining the concentration of microalgae, it requires the generation of a new calibration curve when the environmental conditions (e.g., temperature, light, etc.) change, since the size of microalgae may vary from one condition to another. We propose a novel methodology to determine the number of microalgae in a solution, emphasizing a correlation with optical density and the size distribution of cells. Considering that microalgal physiology is affected by environmental conditions, the proposed procedure allows for the calculation of the concentration of microalgae in changing ambient conditions without requiring the preparation of additional calibration curves.
\end{abstract}

Keywords: microalgae; cell density; calibration curve; dynamic environment.

\section{Introduction and Objective of the Study}

Numerous applications and bioproducts, makes microalgae an interesting subject of investigation [1]-[4]. Intuitively, the concentration of microalgae in a solution is an important factor to quantify the productivity. Cell density is generally defined as the concentration of microalgae in the medium in terms of the number or mass of cells per unit volume. In this work, we will focus on the number density of cells, since it is 
fundamental for understanding the population dynamics of microalgae [5], [6]. The number density of cells is commonly measured with a hemocytometer under a microscope. Moreover, a calibration curve can then be generated to define a correlation between the number density of microalgae and the optical density, which is measured using a spectrophotometer.

An alternative way to determine the number concentration (also called number density) of microalgae is by using automatic counting machines, which are noticeably more expensive. Additionally, some researchers have utilized flow cytometry to obtain additional useful information, such as cell density, pigment concentration and viability [7], [8]. Nevertheless, this paper aims to develop a measuring method that can be applied by anyone, and the following discussion is based on some very common, inexpensive equipment (optical microscope and spectrophotometer). A very large number of studies have utilized calibration curves as an indirect method to measure the cell density of microalgae by correlating optical density with the biomass concentration (in terms of number and/or mass) [9]-[14]. However, in some papers, it is not clear whether the same calibration curve was applied for experiments conducted under variable conditions [15], [16].

In the case where the experimental conditions are unique and do not affect the physiology of cells (e.g., size and composition), constructing a calibration curve is reasonable and very practical. However, it is evident that calibration curves are considered reliable only if the ambient settings are kept constant. When the experiment is performed in changing environments, a calibration curve should be defined for each scenario, since the cellular characteristics may change. For instance, microalgae tend to be smaller at higher temperatures [17]. In outdoor applications, the conditions may easily change (e.g., in 
response to the difference in light and temperature during the day/night shift and the change in temperature among different seasons).

The correlations among wavelength, optical density and intracellular composition has been the subject of several studies that can be found in the literature. Although wellestablished techniques utilizing a multi-wavelength approach that allows the determination of composition, shape and/or concentration of microorganisms (see the works from Garcia Rubio's group [18], [19] and Lantz et al. [20], among others), the usage of calibration curves applied to microorganisms is still extensively used [9], [14], [21], [22]. For example, certain wavelengths can be associated with the concentration of specific components inside microalgal cells, such as shown by Jia et al. [23]. However, the intracellular composition of cells is not a target of this paper.

In the case of microalgae, the optical density is usually measured using a wavelength different from the wavelength of the peak generated by the intracellular pigments. A common choice is $750 \mathrm{~nm}$. The same optical density measurement was performed on different microalgae samples, showing the same results. Griffith et al. [21] showed that pigment changes cause optical density errors at $680 \mathrm{~nm}$ but not at $750 \mathrm{~nm}$ [21]. It was demonstrated that, for different species of microalgae, the error is higher when the wavelength used to measure the optical density is $680 \mathrm{~nm}$. These authors tried to increase the pigment concentration by changing the environmental conditions $\left(\mathrm{NO}_{3}^{-}\right.$concentration in this case) and demonstrated that different concentrations of the pigment affect the measurement at $680 \mathrm{~nm}$ but have no effect at $750 \mathrm{~nm}$. Our spectral curve also showed a pigment peak at $684 \mathrm{~nm}$ (see Figure 1). However, there is no study that makes a clear correlation between environmental conditions, total population number, cell size distribution and pigment concentration. To the best of our knowledge, only one paper has 
taken into account and clearly stated that cells have different characteristics (e.g., density) in different conditions [8], yet no mathematical model to correlate the optical density with the microalgae population (either in terms of number or mass) has been defined. This study considers only a singular wavelength since the main objective of this work is to develop a correlation between optical density and the number concentration of cells. Moving away from this wavelength (close to peaks in particular), the correlation is no longer valid since it has been proven by several researchers that the pigment concentration affects the results [21], [24]. However, the proposed approach can be a good starting point for developing additional correlations with composition and the concentration of cell mass.

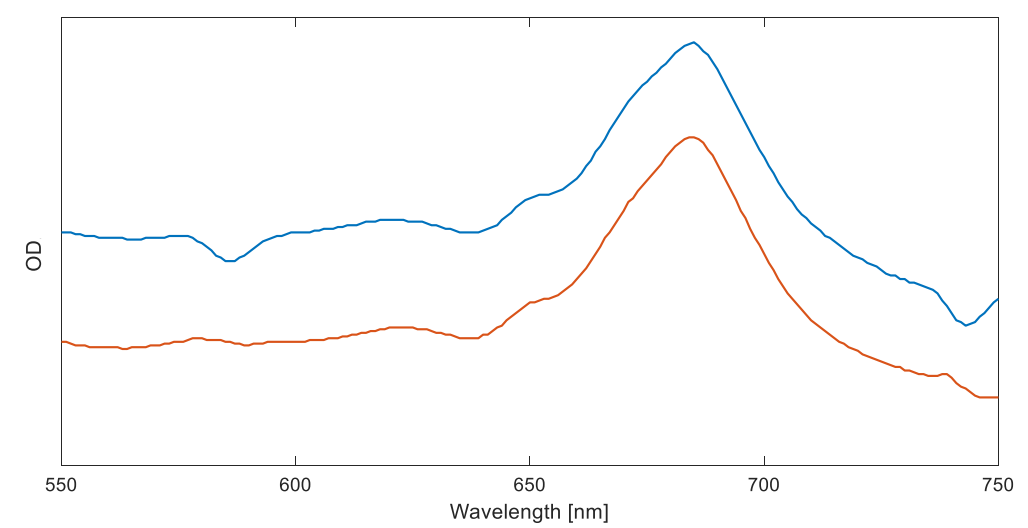

Figure 1 Optical density of two different samples tested in the wavelength range of 550 to $750 \mathrm{~nm}$.

Based on the above considerations, we propose an alternative methodology to define the calibration curve for dynamic biological systems to determine the number density of cells. As already mentioned, the dynamics are introduced by possible variations in the microalgal physiology that commonly occurs when environmental conditions change. In particular, the variations of microalgae sizes are taken into account. This approach may be beneficial for researchers working in the field, and it may be applied to other biological systems.

Some researchers have tried to understand the effect of different environmental conditions 
on the growth of microalgae, and several researchers have noticed that the microalgal life cycle is influenced by environmental conditions [5], [17], [25], [26]. It is well established that microalgae tend to grow larger at lower temperatures and remain smaller at high temperatures [17]. This trend may be caused by the fact that, at high temperatures, microalgae tend to be smaller in order to improve the uptake of nutrients [27]. In addition to confirming the temperature effect, the conclusions drawn by Morimura [5] state that cells mature earlier at higher temperatures. Therefore, it is clear that changing the environmental conditions may affect the physiology of cells in terms of both composition and size. The latter is the principal factor considered in the following discussion. The experiment has been performed on a single species of microalgae, but the procedure can easily be extended to other species, especially those in the same family and/or those that have similar characteristics to the type of cells examined in this work. Furthermore, a potential extension to other biological systems can be investigated in future works.

\section{Materials and Methods}

\subsection{Cultivation of Microalgae}

A strain of Chlorococcum (spherical-shaped, single-celled microalga) was provided by a biodiesel company in China and used for the experimental validation. Cylindrically shaped photobioreactors (PBRs) were utilized for the experiment. White LEDs were installed around the PBR, and the reactor was then placed in a water bath with a temperature controller to maintain the desired temperature. BG-11 medium was used as the nutrient source. The analyses were conducted on six samples. Sample 1 and sample 2 were kept at room temperature (no heating/cooling applied to the system). Samples 3 and 5 were grown at $23{ }^{\circ} \mathrm{C}$, while samples 4 and 6 were grown at $30^{\circ} \mathrm{C}$. In sample 5 , only $20 \% \mathrm{w} / \mathrm{w}$ nutrient concentration was introduced in the reactor, while in sample 6 , only 50 
$\% \mathrm{w} / \mathrm{w}$ was used. The remaining samples used the traditional BG-11 medium. In addition, samples 1, 4 and 6 were collected after 20 days of growth, while the remaining samples were collected after 5 days. All of the samples were then adjusted to the desired calibration range for analysis. The light intensity was 600 lumen (value from LED manufacturer) for tanks 3, 4 and 6; the light intensity was 1020 lumen for tank 5; and no LED light was used for samples 1 and 2 (room light, where 8 fluorescent cool white lamps operating around the room are installed on the ceiling of the lab - corresponding to $\sim 270$ 1x near the PBRs; lights were turned on only during office hours). Air was supplied to all of the samples as the carbon dioxide source and to agitate the system. The main objective of the above explanation is to clarify that microalgae were grown under different conditions hence not having the same effect on the population. Describing the effects of the environmental conditions in different phases (growth, ripening, maturing, division [5]) is not the objective of this work.

\subsection{Correlation Between Optical Density and Number Concentration}

For each sample, five dilution factors were chosen to generate the curve. The same procedure was repeated four times to obtain an accurate value of the $\mathrm{OD}_{750}$. The standard error, $S E$, has been calculated as $S E=S D / \sqrt{\text { Sample Size }}$ where $S D$ is the standard deviation of the sample [28]. The error is shown in Figure 2, but it is small and therefore difficult to detect. To increase the reliability of the results, part of the microalgae solution from each sample was filtered with $0.3 \mu \mathrm{m}$ pore filters to obtain the blank.

After the spectrophotometer (Biochrome Libra S6) measurement was performed, the remaining solution was used for image analysis. A drop of solution was placed on a hemocytometer, and the number concentration, $n$, of the cells was measured. On the other hand, to obtain the size distribution, several pictures of microalgae were taken from the 
original, concentrated solution after vigorous agitation, assuming that the solution was well mixed.

Figure 2 shows the optical densities measured at $750 \mathrm{~nm}$ and the corresponding cell concentrations. A linear regression was performed on these data, and the resulting lines are shown in the same graph.

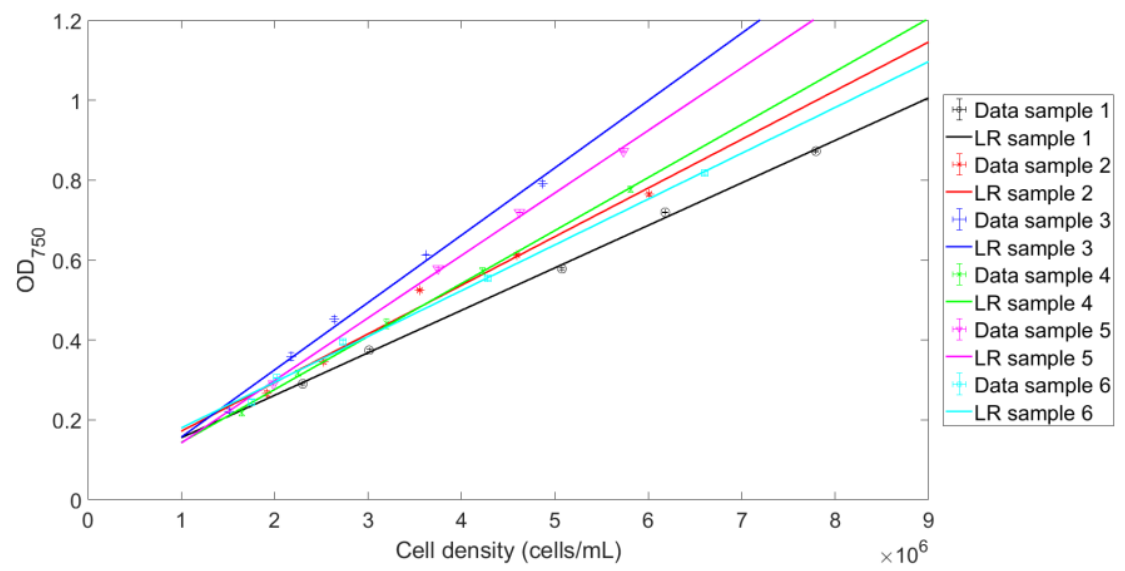

Figure 2 Optical densities for different samples and linear regressions (LR). Sample 1: room light and temperature, BG-11, 20 days of growth; sample 2: room light and temperature, BG-11, 5 days of growth; sample 3: $23^{\circ} \mathrm{C}, 600 \mathrm{Im}, B G-11,5$ days of growth; sample $4: 30^{\circ} \mathrm{C}, 600 \mathrm{Im}, B G-11,20$ days of growth; sample $5: 23^{\circ} \mathrm{C}, 1020 \mathrm{~lm}, 20 \% \mathrm{w} / \mathrm{w} \mathrm{BG}-11,5$ days of growth; sample 6: $30^{\circ} \mathrm{C}, 600 \mathrm{~lm}, 50 \% \mathrm{w} / \mathrm{w} \mathrm{BG}-11,20$ days of growth.

If we assume that the absorbance of the solution is zero in the case in which there are no cells, the lines should initiate from the origin. It is assumed that the correlation for very low concentrations of microalgae is still linear. Figure 3 shows that the correlation would change, forcing the initiating from the origin. The resulting $\mathrm{R}^{2}$ is higher than 0.98 for all the constrained cases. 


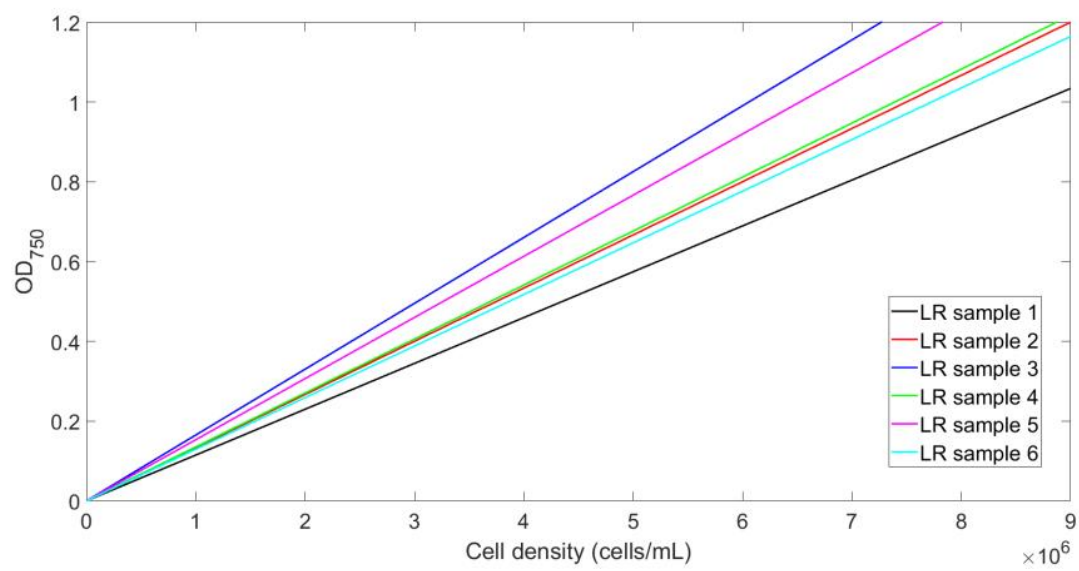

Figure 3 Linear correlation for all samples forced to initiate from the origin. Sample 1: room light and temperature, BG-11, 20 days of growth; sample 2: room light and temperature, BG-11, 5 days of growth; sample $3: 23^{\circ} \mathrm{C}, 600 \mathrm{Im}, B G-11,5$ days of growth; sample $4: 30^{\circ} \mathrm{C}, 600 \mathrm{Im}, B \mathrm{G}-11,20$ days of growth; sample 5: $23^{\circ} \mathrm{C}, 1020 \mathrm{Im}, 20 \% \mathrm{w} / \mathrm{W} B \mathrm{BG}-11,5$ days of growth; sample $6: 30^{\circ} \mathrm{C}, 600 \mathrm{Im}, 50 \% \mathrm{w} / \mathrm{w} B G-11,20$ days of growth.

At this point, it is worth noticing the error that may have been committed by using the same calibration curve when measuring the number density of cells grown in different environmental conditions. Just considering the cases shown in Figure 3, samples 1 and 3 represent the two extremes. If the conditions are those of sample 1, but the curve obtained from sample 3 is used, the error committed can be as high as $43.69 \%$. Nevertheless, this value may be even higher if the range of cell sizes is wider (such as in other species).

Figure 4 shows the size distribution results of the samples (extreme cases). It can be observed that the average size of cells in sample 3 is larger than the average size examined in sample 1. To obtain the size distribution of microalgae, several pictures were taken using an optical microscope. The collected images (containing approximately 400 cells) were analyzed with ImageJ [29]. To draw such a graph, bins of size $0.5 \mu \mathrm{m}$ were utilized. The average size of cells can be calculated using the mean value theorem, and the theorem will be used in the following sections. 


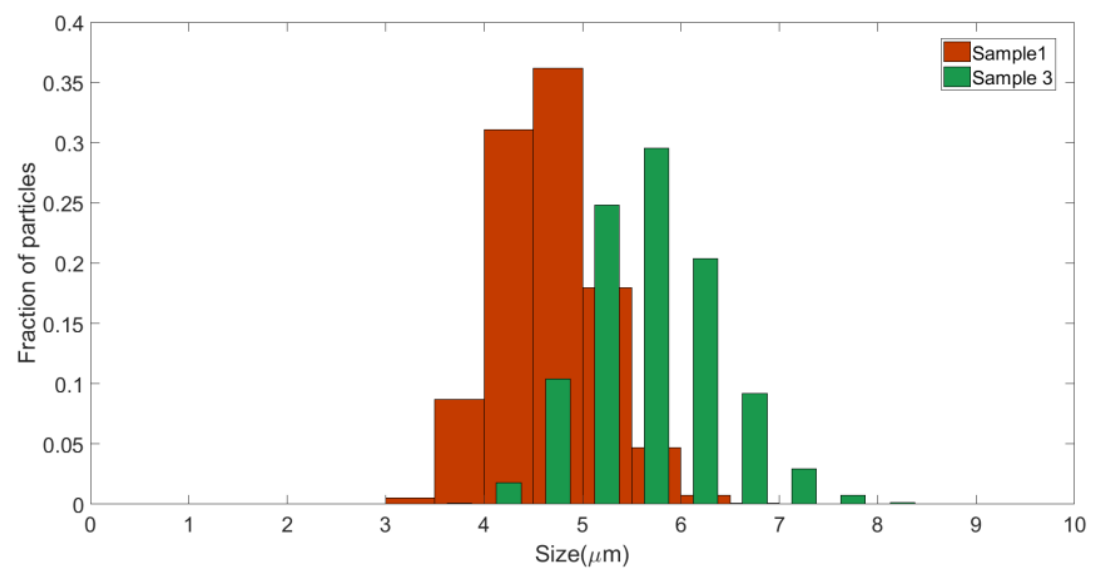

Figure 4 Size distribution of microalgae. Sample 1: room light and temperature, BG-11, 20 days of growth; sample $3: 23^{\circ} \mathrm{C}, 600 \mathrm{Im}, B G-11,5$ days of growth.

\section{Results and Discussion}

\subsection{Results Analyses}

After performing the measurements, it was possible to notice an interesting correlation between the average size of microalgae and the slope of the calibration curve. The sample with larger cells is represented by the curve in Figure 3 with the greater slope. This observation means that at the same optical density, the number of cells counted in sample 3 is much smaller than the number of cells counted in sample 1.

Figure 5 shows the correlation between the average cell diameter and the slope of the calibration curve. The correlation is approximately linear $\left(\mathrm{R}^{2} \approx 0.98\right)$. Figure 5 shows that there is a correlation between the size of microalgae and the optical density that can be represented by the following equation:

$$
\text { Slope }=-0.9206 E-7+0.4441 E-7 \cdot d_{\text {ave }}
$$

The correlation in Equation 1 can be further developed to achieve a direct relationship between optical density and number density of microalgae expressed in cells per mL of solution, while the mean diameter $d_{a v e}$ is expressed in $\mu \mathrm{m}$. The total number of microalgae in the PBR can easily be calculated by multiplying the obtained value $n$ by the overall volume. 


$$
O D_{750}=\left(-0.9206 E-7+0.4441 E-7 \cdot d_{\text {ave }}\right) \cdot n
$$

$n\left[\frac{\text { cells }}{\text { volume }}\right]$ is the number density of microalgae in the reactor, related to the total number of cells by the following equation: $N=n V$. In this case, the number density refers to the whole size domain. Applying Equation 2, it is possible to identify the number of cells in a specific condition by knowing the population size distribution and the optical density. Microalgae can have a size range from $2 \mu \mathrm{m}$ to over $50 \mu \mathrm{m}$ [30]. In our case, Chlorococcum has a size between $2 \mu \mathrm{m}$ and $10 \mu \mathrm{m}$ (at most - extreme sizes) under different conditions of light, temperature and nutrient concentration.

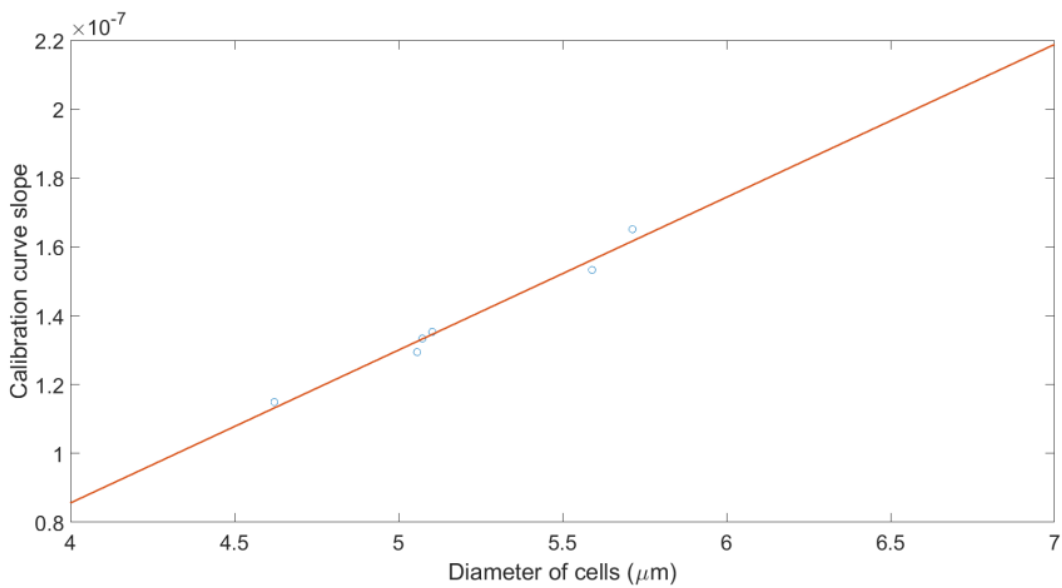

Figure 5 Linear correlation between the slope of the calibration curve and the average diameter of the microalgae population.

The calibration curve range extends from sample 1 to sample 3 as shown by the red area in Figure 6; therefore, the proposed model can, momentarily, cover only that range. 


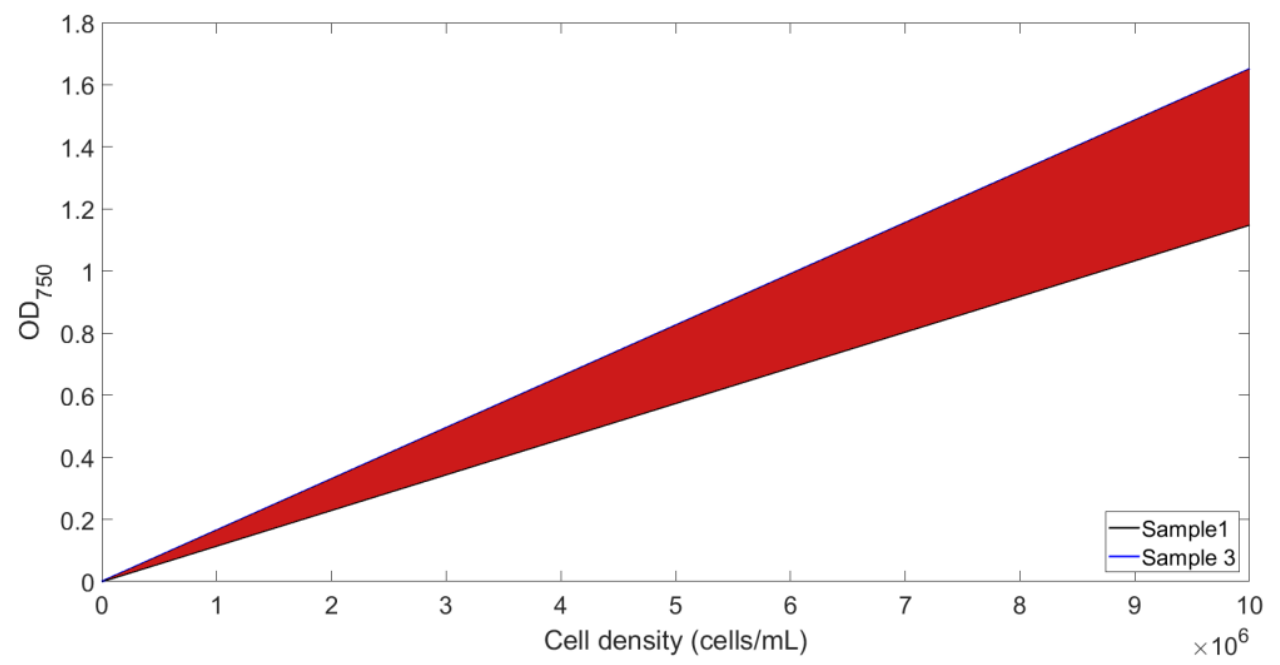

Figure 6 The red area represents the range in which the model has been verified. The black and blue lines show the calibration curves for critical size conditions of microalgae (as seen in the proposed case studies). Sample 1: room light and temperature, BG-11, 20 days of growth; sample 3: $23^{\circ} \mathrm{C}, 600 \mathrm{Im}, B G-11,5$ days of growth.

\subsection{Additional Considerations of the Results}

The amount of pigment inside the cells is not known. However, it is well established that remaining in the peak region of the spectra (which characterizes the presence of chlorophyll) is not suggested, since cells with a higher chlorophyll content would show a higher value of optical density than cells with a lower concentration. Additional information regarding why $750 \mathrm{~nm}$ is one of the suggested wavelengths utilized to measure the concentration of microalgae can be found in Kirk's book [24]. This reference, once more, confirms the theory suggested by Griffith [21]. Therefore, the main reason we are not interested in the pigment concentration is that, as stated clearly by other researchers [21], [24], the pigment does not influence the absorbance of the microalgae solution if the measurement is taken using a wavelength far from the peak. In our opinion, if the pigments inside the cells are not affecting the measurement, a possible reason may be the distribution of the size of the cells inside the system. It is reasonable to think that a certain number of small cells may present the same measurement as a smaller number of large cells. 
The greatest potential of this methodology for determining the calibration curve is the possibility that it could be used in dynamic conditions. This calibration curve can be applied for any change in microalgae size, regardless of the causes of this change. A change in the cell size distribution would not require the determination of a new calibration curve because we are working at a wavelength at which the influence of pigment concentration does not affect the measurements. In other words, it would be sufficient to obtain 2-4 calibration curves under different conditions to define the range of interest.

The idea can be applied to the cells in terms of dry mass in which the density of cells is not strongly affected by the environmental conditions. However, the relationship in this case would be more complex. The size of the cells is not the only factor affecting the weight of microalgae; the concentration of internal substances becomes more relevant. Therefore, the change of the internal composition does not allow for the model to be applied to the dry biomass. For example, in some specific conditions, the cells tend to have higher concentrations of lipids and, as a consequence, the density of cells will be affected. However, if the internal cell density is known, determining the relationship between the number of cells and dry weight becomes possible. This fact may be the basis for future investigations, since it would be possible to determine a correlation between the density of the cells, the weight of the cells and the concentration of specific substances inside the cells (e.g., lipids).

The application of the suggested model to different species of microalgae would allow for the development of a database in which, based on the microalgae species, it would be possible to obtain the parameters needed to define the range of the calibration curve.

\section{Conclusions}


A new model to define correlations among optical density, distribution of cell size and number of microalgae has been proposed in this paper. The possibility of utilizing this methodology to determine the number of microalgae can be very useful to researchers in the field, reducing the required work yet maintaining good quality results. The model can be used to calculate the number of cells per unit volume of solution under dynamic environmental conditions. This model would allow for better tracking of the changes in microalgae population inside a photobioreactor. Future investigations may involve the dry mass of microalgae and the concentration of specific cellular components.

\section{Acknowledgements}

The authors gratefully acknowledge the support from Hong Kong RGC in form of $\mathrm{PhD}$ Fellowship to Pahija Ergys (PF13-15834) and for the GRF16211117 funding. The authors also acknowledge AirProduct LTD for financing the project.

\section{Informed consent, human/animal rights}

No conflicts, informed consent, human or animal rights applicable.

\section{Contributions of authors}

Ergys Pahija designed and performed the experiments, analyzed the data, wrote and reviewed the paper, prepared the figures and/or tables and worked in the model development. Chi-Wai Hui has contributed in the experiment design, in the model development as well as in reviewing drafts of the paper.

\section{References}

[1] Y. S. Shin, H. Il Choi, J. W. Choi, J. S. Lee, Y. J. Sung, and S. J. Sim, "Multilateral approach on enhancing economic viability of lipid production from microalgae: A review.," Bioresour. Technol., vol. 258, pp. 335-344, Jun. 2018.

[2] K. W. Chew et al., "Microalgae biorefinery: High value products perspectives.," Bioresour. Technol., vol. 229, pp. 53-62, Apr. 2017.

[3] M. Koller, A. Muhr, and G. Braunegg, "Microalgae as versatile cellular factories 
for valued products," Algal Res., vol. 6, pp. 52-63, Oct. 2014.

[4] J. A. Garrido-Cardenas, F. Manzano-Agugliaro, F. G. Acien-Fernandez, and E. Molina-Grima, "Microalgae research worldwide," Algal Res., vol. 35, pp. 50-60, Nov. 2018.

[5] Y. Morimura, "Synchronous Culture of Chlorella," Plant and Cell Physiology, vol. 1. pp. 49-62, 1959.

[6] E. Pahija, P. Y. Lee, and C.-W. Hui, "A Revision of Population Balance Equation Applied to Microalgae with Birth, Growth, and Death," Process Integr. Optim. Sustain., pp. 1-17, Jul. 2018.

[7] J. Toepel, C. Wilhelm, A. Meister, A. Becker, and M. del C. Martinez-Ballesta, "Cytometry of freshwater phytoplankton.," Methods Cell Biol., vol. 75, pp. 375407, 2004.

[8] M. Chioccioli, B. Hankamer, and I. L. Ross, "Flow cytometry pulse width data enables rapid and sensitive estimation of biomass dry weight in the microalgae Chlamydomonas reinhardtii and Chlorella vulgaris.," PLoS One, vol. 9, no. 5, p. e97269, 2014.

[9] Q. Gong, Y. Feng, L. Kang, M. Luo, and J. Yang, "Effects of Light and pH on Cell Density of Chlorella Vulgaris," Energy Procedia, vol. 61, pp. 2012-2015, 2014.

[10] A. S. Mirón, M.-C. C. García, F. G. Camacho, E. M. Grima, and Y. Chisti, "Growth and biochemical characterization of microalgal biomass produced in bubble column and airlift photobioreactors: studies in fed-batch culture," Enzyme Microb. Technol., vol. 31, pp. 1015-1023, 2002.

[11] M. L. Bartley, W. J. Boeing, A. A. Corcoran, F. O. Holguin, and T. Schaub, "Effects of salinity on growth and lipid accumulation of biofuel microalga Nannochloropsis salina and invading organisms," Biomass and Bioenergy, vol. 54, no. 3, pp. 83-88, Jul. 2013.

[12] J. M. S. Rocha, J. E. C. Garcia, and M. H. F. Henriques, "Growth aspects of the marine microalga Nannochloropsis gaditana.," Biomol. Eng., vol. 20, no. 4-6, pp. 237-42, Jul. 2003.

[13] N. M. Franklin, J. L. Stauber, S. C. Apte, and R. P. Lim, "Effect of initial cell density on the bioavailability and toxicity of copper in microalgal bioassays," Environ. Toxicol. Chem., vol. 21, no. 4, pp. 742-751, 2002.

[14] S.-S. Suh, M. Park, J. Hwang, E.-J. Kil, S. Lee, and T.-K. Lee, "Detection of the dinoflagellate, Cochlodinium polykrikoides, that forms algal blooms using sandwich hybridization integrated with nuclease protection assay.," Biotechnol. Lett., vol. 38, no. 1, pp. 57-63, Jan. 2016.

[15] H. Tang, N. Abunasser, M. E. D. Garcia, M. Chen, K. Y. Simon Ng, and S. O. Salley, "Potential of microalgae oil from Dunaliella tertiolecta as a feedstock for biodiesel," Appl. Energy, vol. 88, no. 10, pp. 3324-3330, Oct. 2011.

[16] M. Chen, H. Tang, H. Ma, T. C. Holland, K. Y. S. Ng, and S. O. Salley, "Effect of nutrients on growth and lipid accumulation in the green algae Dunaliella tertiolecta," Bioresour. Technol., vol. 102, no. 2, pp. 1649-55, Jan. 2011.

[17] J. A. Raven and R. J. Geider, "Temperature and algal growth," New Phytol., vol. 110, no. 4, pp. 441-461, Dec. 1988.

[18] M. R. Callahan, J. B. Rose, and L. García-Rubio, "Use of Multiwavelength Transmission Spectroscopy for the Characterization of Cryptosporidium parvum Oocysts: Quantitative Interpretation,” Environ. Sci. Technol., vol. 37, no. 22, pp. 
5254-5261, Nov. 2003.

[19] J. M. Smith, A. Roth, D. E. Huffman, Y. M. Serebrennikova, J. Lindon, and L. H. García-Rubio, "Multi-Wavelength Transmission Spectroscopy Revisited for Micron and Submicron Particle Characterization," Appl. Spectrosc., vol. 66, no. 10, pp. 1186-1196, Oct. 2012.

[20] A. Eliasson Lantz, P. Jørgensen, E. Poulsen, C. Lindemann, and L. Olsson, "Determination of cell mass and polymyxin using multi-wavelength fluorescence," J. Biotechnol., vol. 121, no. 4, pp. 544-554, Feb. 2006.

[21] M. J. Griffiths, C. Garcin, R. P. van Hille, and S. T. L. Harrison, "Interference by pigment in the estimation of microalgal biomass concentration by optical density.," J. Microbiol. Methods, vol. 85, no. 2, pp. 119-23, May 2011.

[22] D. Dufour et al., "Native and myeloperoxidase-oxidized low-density lipoproteins act in synergy to induce release of resolvin-D1 from endothelial cells," Atherosclerosis, vol. 272, pp. 108-117, May 2018.

[23] F. Jia, M. Kacira, and K. Ogden, "Multi-Wavelength Based Optical Density Sensor for Autonomous Monitoring of Microalgae," Sensors, vol. 15, no. 9, pp. 22234-22248, Sep. 2015.

[24] J. T. O. Kirk, Light and Photosynthesis in Aquatic Ecosystems. Cambridge: Cambridge University Press, 2010.

[25] K. F. Edwards, M. K. Thomas, C. A. Klausmeier, and E. Litchman, "Phytoplankton growth and the interaction of light and temperature: A synthesis at the species and community level," Limnol. Oceanogr., vol. 61, no. 4, pp. 12321244, Jul. 2016.

[26] C. J. Unkefer et al., "Review of the algal biology program within the National Alliance for Advanced Biofuels and Bioproducts," Algal Res., vol. 22, pp. 187215, Mar. 2017.

[27] D. C. Reuman, R. D. Holt, and G. Yvon-Durocher, "A metabolic perspective on competition and body size reductions with warming," J. Anim. Ecol., vol. 83, no. 1, pp. 59-69, Jan. 2014.

[28] D. G. Altman and J. M. Bland, "Standard deviations and standard errors," $B M J$, vol. 331 , no. 7521 , p. 903 , Oct. 2005.

[29] C. A. Schneider, W. S. Rasband, and K. W. Eliceiri, "NIH Image to ImageJ: 25 years of image analysis.," Nat. Methods, vol. 9, no. 7, pp. 671-5, Jul. 2012.

[30] A. J. Dassey and C. S. Theegala, "Harvesting economics and strategies using centrifugation for cost effective separation of microalgae cells for biodiesel applications," Bioresour. Technol., vol. 128, pp. 241-5, Jan. 2013. 